\title{
Crustal structure beneath the Indochina peninsula from teleseismic receiver functions
}

\author{
Ling Bai, ${ }^{1}$ Xiaobo Tian, ${ }^{2}$ and Jeroen Ritsema ${ }^{1}$ \\ Received 27 July 2010; revised 18 October 2010; accepted 28 October 2010; published 24 December 2010.
}

[1] We analyze teleseismic receiver functions to determine the crustal structure beneath the Indochina peninsula which is located immediately south-east of the eastern Himalayan syntaxis basin. We found that the Indochina peninsula is characterized by a thin $(\sim 31 \mathrm{~km})$ crust with a low $\mathrm{Vp} / \mathrm{Vs}$ ratio $(\sim 1.68)$. The intra-lower crustal low-velocity zone (LVZ) is observed beneath the northwestern part of our study region. We hypothesize that it is an extension of the lower crustal LVZ observed beneath the southeastern Tibet and the South China block and that it terminates at the Dien Bien Phu Fault (DBPF). A LVZ observed in the upper crust beneath southeast of the DBPF indicates that the crust is ductile and earthquakes are rare. Citation: Bai, L., X. Tian, and J. Ritsema (2010), Crustal structure beneath the Indochina peninsula from teleseismic receiver functions, Geophys. Res. Lett., 37, L24308, doi:10.1029/2010GL044874.

\section{Introduction}

[2] The collision between Indian and Eurasian plates, that began at approximately $50 \mathrm{Ma}$ [Huchon et al., 1994], has influenced the structure of the Earth far beyond the HimalayaTibet orogeny. Situated immediately southeast of the eastern Himalayan syntaxis, the Indochina peninsula bends southeastward as a consequence of continental extrusion from southern Tibet and the opening of the South China Sea. The Indochina peninsula is in the Sunda block, a rigid block in southeastern Asia that is separated from the South China block (SCB) by the Red River Fault (RRF) to the northeast and from the Burma block by the Sagaing Fault to the northwest [Iwakuni et al., 2004] (Figure 1). Huchon et al. [1994] inferred that the maximum horizontal component of the stress field was oriented E-W before collision and N-S currently. Large-scale NW-SE and NE-SW trending strikeslip faults are widely distributed. Sedimentary basins in northern Vietnam and at the Gulf of Thailand are the result of dip-slip fault activity throughout the Cenozoic [Tapponnier et al., 1982].

[3] Low-velocity anomalies in the crust and upper mantle beneath Indochina peninsula have been revealed from seismic tomography [Huang et al., 2003; Lebedev and Nolet, 2003]. However, the resolution of the tomographic images is low partly because there is only one broadband station (CHTO) in the region. Receiver-function (RF) studies in

\footnotetext{
${ }^{1}$ Department of Geological Sciences, University of Michigan, Ann Arbor, Michigan, USA.

${ }^{2}$ Institute of Geology and Geophysics, Chinese Academy of Sciences, Beijing, China.

Copyright 2010 by the American Geophysical Union. 0094-8276/10/2010GL044874
}

central and southeastern Tibet [Ozacar and Zandt, 2004; Xu et al., 2007] have provided evidence for a low-velocity zone (LVZ) in the lower crust and intermediate-to-high average crustal Poisson's ratios. These observations suggest the presence of a crustal flow channel and that the crust and mantle are decoupled. However, whether this LVZ extends into the Indochina peninsula is unknown.

[4] SKS splitting analysis [Bai et al., 2009] has indicated that the delay time between the fast and slow shear waves is larger beneath Indochina than beneath eastern Tibet where the crust and mantle have been deformed substantially. The fast polarization directions revealed a pronounced transition from NW to NE, which suggests that the Indochina peninsula is deformed along with the Tibetan plateau to the $\mathrm{N}$ but deformed along with the South China Sea in the $\mathrm{S}$.

[5] In order to study the crust beneath the Indochina peninsula, we analyze RFs using new data from a temporary broadband seismograph array in Vietnam and IRIS stations KMI, QIZ and CHTO. We estimate the Moho depths, Vp/Vs ratios, and shear velocity profiles of the crust. Our analysis provides further insights into the origin and geologic history of the southeast Asia.

\section{Data and Methods}

[6] We analyze waveforms from the Vietnam broadband seismograph array, which was operated by the Earthquake Research Institute, the University of Tokyo (between February 2000 and October 2005) as a part of the Ocean Hemisphere network Project (http://www.eri-ndc.eri.u-tokyo.ac.jp/). This array consisted of six temporary broadband (Guralp CMG-3T) seismometers with a sampling rate of $50 \mathrm{~Hz}$ (Figure 1 and Table S1). In addition, we analyze waveforms from the permanent stations KMI, QIZ and CHTO in the region.

[7] The RF technique has been widely applied to study the crust and upper mantle beneath a seismic station. RFs are obtained by deconvolving the vertical component from the radial and transverse component waveforms of $\mathrm{P}$ coda. The technique effectively isolates shear wave signals due to conversions and reflections in the crust from earthquake source and lower mantle propagation. Here, we calculate $P$-to- $S$ RFs using the frequency-domain source equalization deconvolution methods of Langston [1979] and Ammon [1991]. The pre-processing includes data quality checks, windowing of waveforms, and rotation of N-S and E-W waveform recordings into radial and transverse components. To remove highfrequency noise, we apply a low-pass Gaussian filter, which has a gain of approximately 0.1 at $1.0 \mathrm{~Hz}$. A water level of 0.0001 is used to stabilize the RF deconvolution. To obtain stacked RF images, all records are moveout-corrected to a common slowness of $0.059 \mathrm{~s} / \mathrm{deg}$, which is the slowness of a 


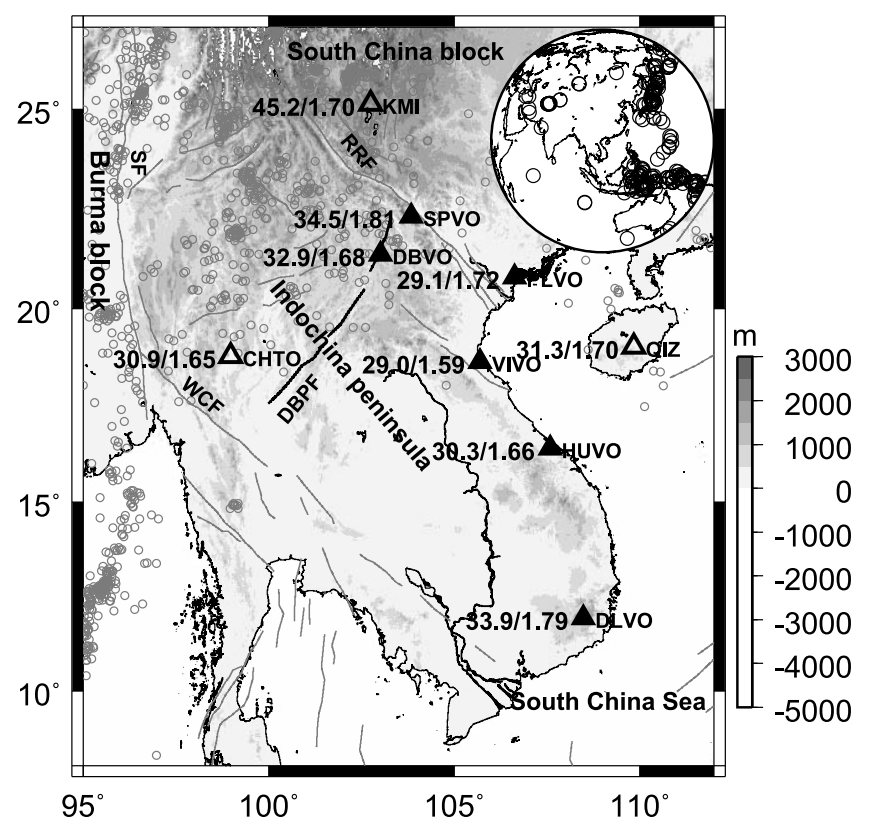

Figure 1. Map of the study region showing the Vietnam array stations (solid triangles) and IRIS stations (open triangles), and regional earthquakes with $\mathrm{M} \geq 3$ (depth $\leq$ $40 \mathrm{~km}$ ) between 1964/01/01 and 2005/12/31 (gray circles). The background shows ETOPO5 topography and lines are active faults: DBPF $=$ Dien Bien Phu Fault (black lines); $\mathrm{RRF}=$ Red River Fault; SF $=$ Sagaing Fault; WCF $=$ Wang Chao Fault. Moho depth $(H)$ and $\mathrm{Vp} / \mathrm{Vs}$ ratio $(\kappa)$ are indicated at the left of each station. The insert shows the epicenters of the events used for RF analysis.

$\mathrm{P}$ wave for a 50-km deep source and an epicentral distance of $65^{\circ}$, based on the IASP91 model [Kennett and Engdahl, 1991].

[8] We estimate the average thickness and $V_{P} / V_{S}$ ratio of the crust using the $H-\kappa$ stacking method of $Z h u$ and Kanamori [2000]. In this approach the amplitudes of the $P_{S}$ signal and the multiples $P_{P} P_{S}$ and $P_{P} S_{S}+P_{S} P_{S}$ are simultaneously stacked and analyzed. Weights of $0.5,0.3$, and 0.2 are used to balance the contributions from these three phases. The Poisson's ratio is calculated using $\sigma=\frac{1}{2}-\frac{1}{2}\left(V_{P}^{2} / V_{S}^{2}\right)-1^{-1}$. We estimate shear velocity profiles in the crust by leastsquares inversion [Ammon et al., 1990] of RFs with highamplitude $P s$ phases and similar waveforms from a small back-azimuth range. The initial $\mathrm{S}$-wave velocity model with $2-3 \mathrm{~km}$ thick layers is derived from the model of Huang et al. [2003] and PREM [Dziewonski and Anderson, 1981]. The P-wave velocity and Moho depth are determined from the $H-\kappa$ analysis. Density is determined using $\rho=0.32 V_{P}+0.77$ [Berteussen, 1977].

\section{Results}

\subsection{Receiver Function Image}

[9] A total of 385 individual RFs are obtained from 217 events (see Figure 1). All radial-component RFs are included

\footnotetext{
${ }^{1}$ Auxiliary materials are available in the HTML. doi:10.1029/ 2010 GL044874.
}

in the auxiliary materials. ${ }^{1}$ There are no obvious phases observed in transverse RFs, indicating that there is no clear presence of crustal anisotropy or dipping layers at shallow depths [Savage, 1998]. At all stations, $P_{S}$ phases are clearly visible on individual and stacked RFs between 3-5 s after direct $P$. Figure 2 shows examples of the radial and transverse RFs from station VIVO and SPVO. At VIVO, the signals with positive polarity at $\sim 3 \mathrm{~s}$ and $\sim 11 \mathrm{~s}$ and the signal with negative polarity at $\sim 15 \mathrm{~s}$ correspond to the $P_{S}, P_{P} P_{S}$ and $P_{P} S_{S}+P_{S} P_{S}$ phases, respectively. A strong negativepolarity phase at $\sim 9 \mathrm{~s}$ is either due to interfering multiples from an intra-crustal layer or due to a $P_{S}$ conversions from an discontinuity at $\sim 60 \mathrm{~km}$ depth. Station SPVO is located directly on the RRF, which is a major tectonic structure in the study area. The complicated RFs indicate that the crust beneath SPVO is highly heterogeneous. $P_{S}$ arrivals at $\sim 5 \mathrm{~s}$ are identified on individual and stacked radial RFs. We identify the positive signal at $\sim 15 \mathrm{~s}$ and the negative signal at $\sim 20 \mathrm{~s}$ as $P_{P} P_{S}$ and $P_{P} S_{S}+P_{S} P_{S}$ phases.

\subsection{Crustal Thickness and $\mathrm{Vp} / \mathrm{Vs}$ Ratio}

[10] The crustal thickness $(H)$ and average $\mathrm{Vp} / \mathrm{Vs}$ ratio $(\kappa)$ for all stations estimated by the $H-\kappa$ method are shown in Figures 1 and 3 and also listed in Table S1. Since there is only a single maximum in the $H-\kappa$ contour map for a reasonable range of values, 'average' values of $H$ and $\kappa$ for the crust can be determined. For the three IRIS stations, $H$ and $\kappa$ have been estimates previously: $H=44.1 \pm 0.3 \mathrm{~km} ; \kappa=$ $1.705 \pm 0.015$ for KMI, $H=32.0 \pm 0.2 \mathrm{~km} ; \kappa=1.708 \pm$ 0.010 for QIZ [Chen et al., 2010] and $H=29.6 \pm 0.8 \mathrm{~km}$; $\kappa=1.878 \pm 0.026$ for CHTO [Hu et al., 2008]. Our results are in good agreement with those studies, except for the $\kappa$ estimates by $\mathrm{Hu}$ et al. [2008], who used a limited number of records.

[11] The crustal thickness $H$ decreases by about $10 \mathrm{~km}$ across the southwestern margin of the SCB into the Indochina peninsula. This observation is consistent with estimates from seismic sounding [Teng et al., 2003]. The thickest crust $(H=45.2 \mathrm{~km})$ and highest $\mathrm{Vp} / \mathrm{Vs}$ ratio $(\kappa=1.81)$ are resolved for station KMI, which is located in the SCB, and for station SPVO. For the other stations, the average crustal thickness is $H=31.1 \mathrm{~km}$ and the $\mathrm{Vp} / \mathrm{Vs}$ ratio is $\kappa=1.68$, which corresponds to a Poisson's ratio of $\sigma=0.22$. These values are significantly lower than the global average values of $34 \mathrm{~km}$ and 1.78 for the continental crust [Zandt and Ammon, 1995]. The thinnest crust of $29 \mathrm{~km}$ and the lowest $\mathrm{Vp} / \mathrm{Vs}$ ratio of $1.59(\sigma=0.17)$ are observed at station VIVO, which is located close to the shore of the South China Sea.

\subsection{S-Wave Velocity Structure}

[12] Figure 4 shows the shear velocity profiles obtained from the least-square inversion of the RFs and the fit between the recorded and synthetic RFs. We define the LVZ as the region where the velocity is lower than the initial model in comparison with the surrounding depth intervals with velocities higher than the initial model. The thickness of the upper crust (defined by shear velocity $<3.5 \mathrm{~km} / \mathrm{s}$ ) range from 12 to $20 \mathrm{~km}$. A lower crustal LVZ is present beneath station KMI in the SCB and stations DBVO, SPVO, and $\mathrm{CHTO}$ in the northwestern region of the Indochina peninsula at a depth of 20-30 km, as constrained by the negative polarity arrivals at $\sim 3 \mathrm{~s}$ in the RFs. The shear velocity profile for station SPVO is otherwise complex due to the heteroge- 


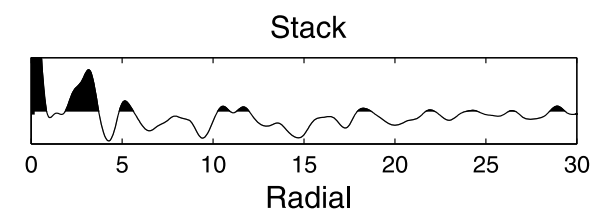

(a)
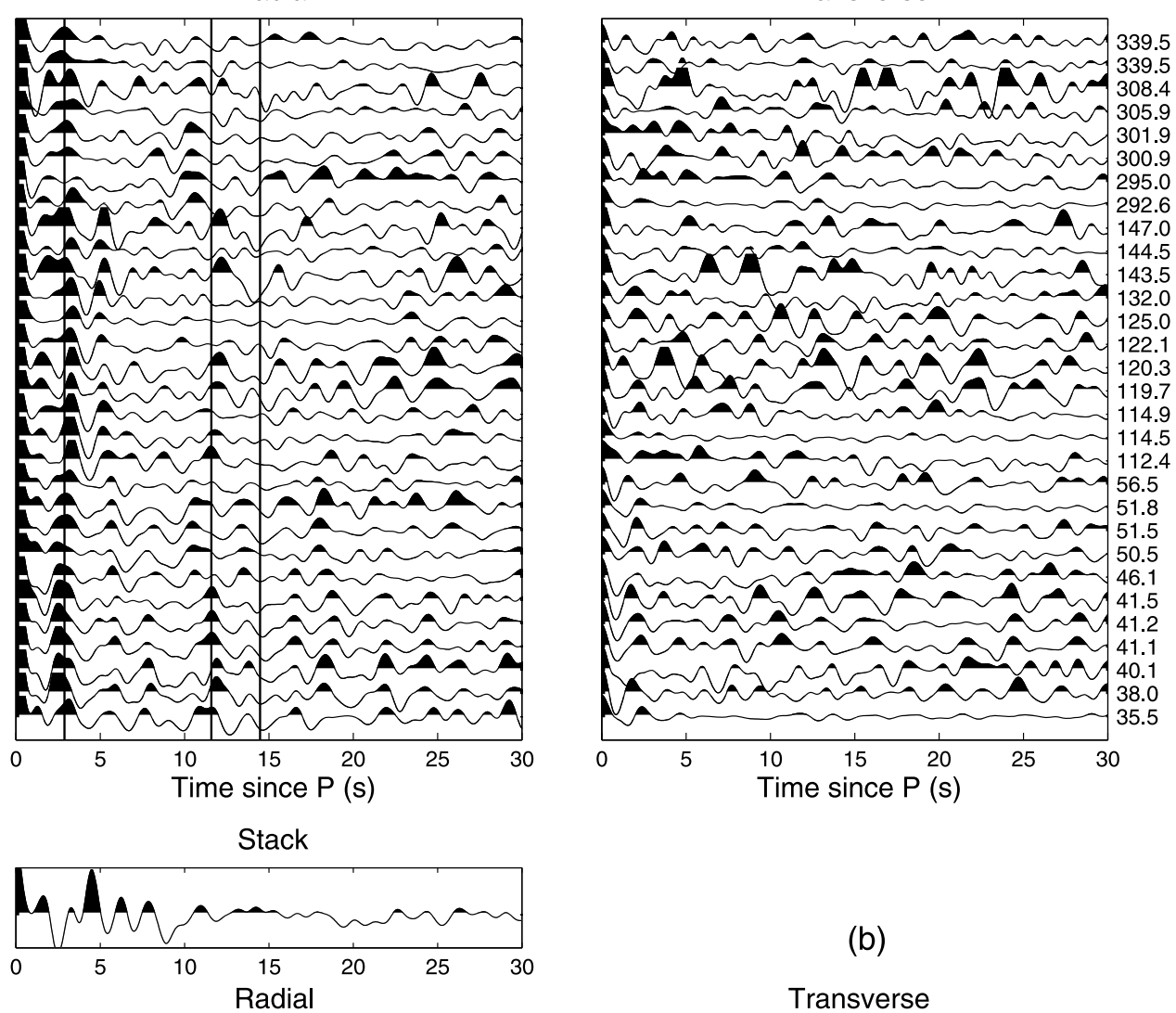

(b)
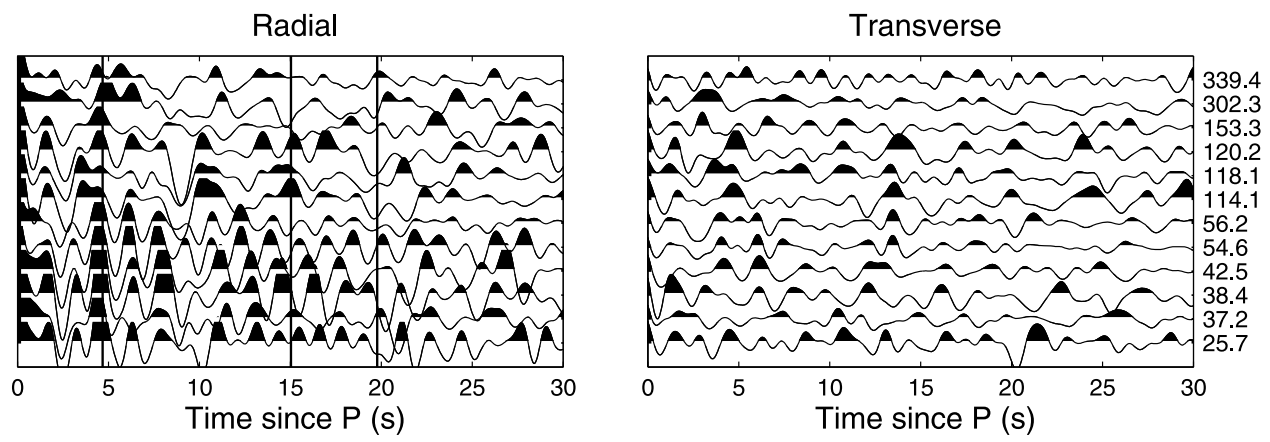

Figure 2. (left) Radial and (right) transverse receiver functions for stations (a) VIVO and (b) SPVO. The records are ordered by increasing back azimuth, as indicated to the right. Stacked radial RFs are shown at the top. Solid lines indicate expected arrival times of $P_{S}$ and the multiples $P_{P} P_{S}$ and $P_{P} S_{S}+P_{S} P_{S}$.

neous crustal structure near the RRF. In contrast, an upper crustal LVZ is observed beneath stations PLVO, VIVO, DLVO, and CHTO in the southeastern part of the Indochina peninsula and station QIZ on Hainan island. At station VIVO, the LVZ has a thickness of $\sim 8 \mathrm{~km}$, which is constrained by the negative arrivals at $1-2 \mathrm{~s}$. The presence of LVZ in the shear velocity profiles improves the fit to the RF (see Figure S10).

\section{Conclusions}

[13] We have discussed the analysis of receiver functions recorded at temporary stations in Vietnam and nearby global network stations in southeastern Asia. We draw the following conclusions: (1) The Indochina peninsula is characterized by a relatively thin crust $(H=31.1 \mathrm{~km})$. (2) A lower crustal low-velocity zone (LVZ) is present beneath the northwestern part of the Indochina peninsula. It connects with the large-scale crustal LVZ beneath central and southeastern Tibet [Ozacar and Zandt, 2004; Xu et al., 2007], and beneath the orogenic belts of the SCB [ Li et al., 2009; Bai et al., 2010] that represent the flow channel. It terminates at the Dien Bien Phu Fault, which is a major tectonic feature in the study region and may be the northern boundary of the postulated Sunda plate [Bird, 2003]. (3) The Poisson's ratio 


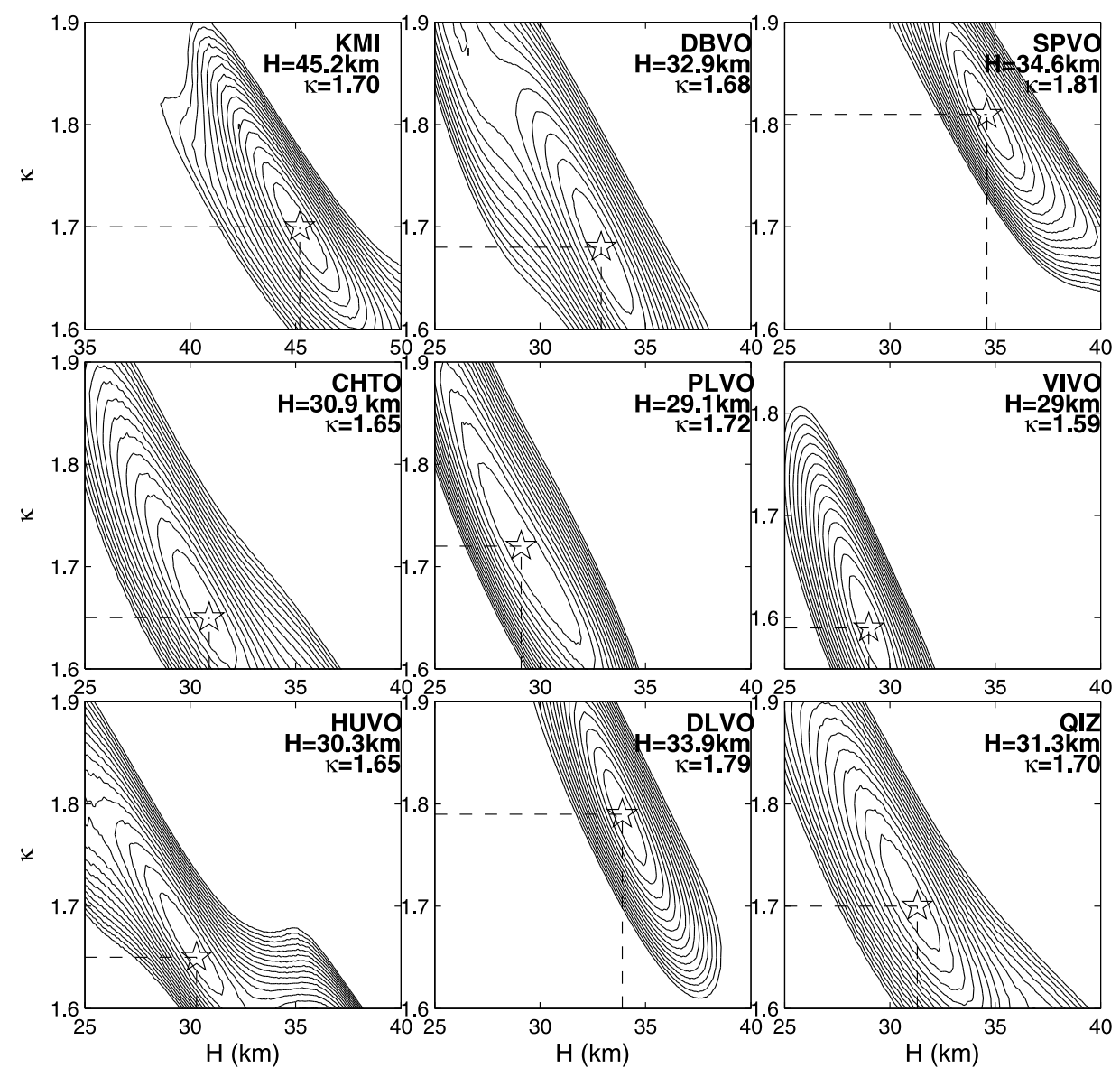

Figure 3. Contour maps showing misfit as a function of crustal thickness $H$ and $\mathrm{Vp} / \mathrm{Vs}$ ratio $\kappa$ for all stations. Contour lines with an interval of 0.02 show stacking amplitudes of radial RFs for the Moho conversion and its multiples. The asterisk indicates minimum misfit. Station names and the optimal parameters are indicated at the top right corner of each panel. 

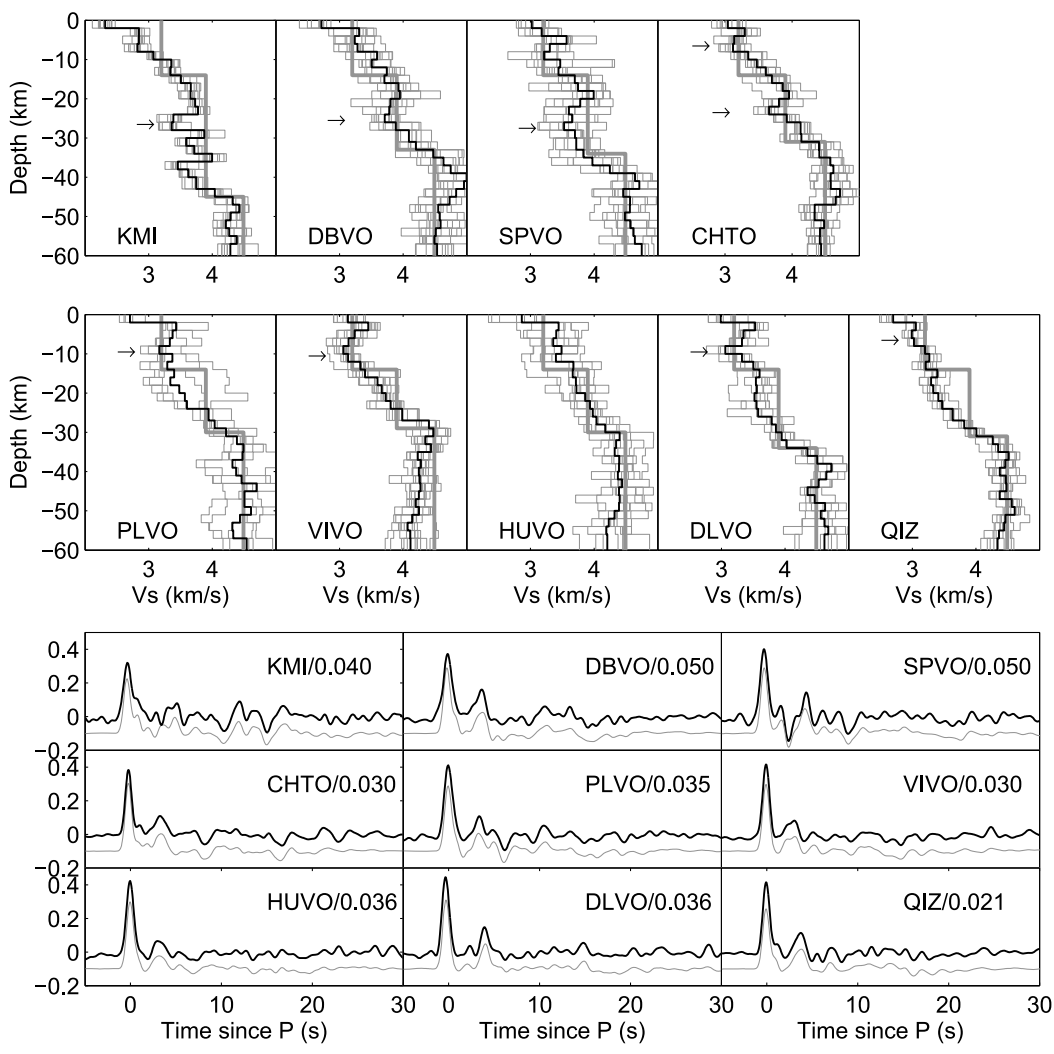

Figure 4. (top) Shear velocity profiles and (bottom) receiver function fits for all stations. The top panels show the initial model (thick gray lines), models obtained from all RFs chosen for inversion (thin gray lines), and the preferred model (black lines). Arrows indicate estimated low-velocity zones. The bottom panels compare the stacked RFs (black curves) and synthetic RFs (gray curves). The RMS misfits between the observed and synthetic waveforms are indicated after each station name.

beneath the Indochina peninsula is low $(\sigma=0.22)$ compared to other continental regions. The crustal composition consists mainly of metasedimentary and silicic intrusive rocks, without mafic or ultramafic components [e.g., Christensen, 1996]. (4) There is no evidence for crustal flow beneath the Indochina peninsula because the Poisson's ratio of 0.22 in average is low. (5) An upper crustal LVZ is detected beneath the southeastern part of the Indochina peninsula and Hainan island. Here, the upper crust is ductile and earthquakes are rare. (6) We do not find evidence for strong anisotropic layering in the crust.

[14] Acknowledgments. We thank the Earthquake Research Institute, the University of Tokyo, for providing Vietnam array data. The IRIS/DMC provided global network waveform data. We are grateful to Editor Michael Wysession and two anonymous reviewers for constructive comments.We used analytical software written by Charles Ammon. The Generic Mapping Tools were used to prepare the figures. This research was partially funded by NSF grant EAR-0944167.

\section{References}

Ammon, C. J. (1991), The isolation of receiver effects from teleseismic P waveforms, Bull. Seismol. Soc. Am., 81, 2504-2510.

Ammon, C. J., G. E. Randall, and G. Zandt (1990), On the non-uniqueness of receiver function inversions, J. Geophys. Res., 95, 15,303-15,318.

Bai, D., et al. (2010), Crustal deformation of the eastern Tibetan plateau revealed by magnetotelluric imaging, Nat. Geosci., 3, 358-362.

Bai, L., T. Iidaka, H. Kawakatsu, Y. Morita, and N. Q. Dzung (2009), Upper mantle anisotropy beneath Indochina block an adjacent regions from shear-wave splitting analysis of Vietnam array data, Phys. Earth Planet. Inter., 176, 33-43.
Berteussen, K. A. (1977), Moho depth determinations based on spectral ratio analysis of NORSAR long-period P waves, Phys. Earth Planet. Inter., 31, 313-326.

Bird, P. (2003), An updated digital model of plate boundaries, Geochem. Geophys. Geosyst., 4(3), 1027, doi:10.1029/2001GC000252.

Chen, Y., F. Niu, R. Liu, Z. Huang, H. Tkalcić, L. Sun, and W. Chan (2010), Crustal structure beneath China from receiver function analysis, J. Geophys. Res., 115, B03307, doi:10.1029/2009JB006386.

Christensen, N. I. (1996), Poisson's ratio and crustal seismology, J. Geophys. Res., 101, 3139-3156.

Dziewonski, A. M., and D. L. Anderson (1981), Preliminary reference Earth model, Phys. Earth Planet. Inter., 25, 297-356.

Hu, J., H. Yang, and H. Zhao (2008), Structure and significance of S-wave velocity and Poisson's ratio in the crust beneath the eastern side of the Qinghai-Tibet plateau, Pure Appl. Geophys., 165, 829-845.

Huang, Z., W. Su, Y. Peng, Y. Zheng, and H. Li (2003), Rayleigh wave tomography of China and adjacent regions, J. Geophys. Res., 108(B2), 2073, doi:10.1029/2001JB001696.

Huchon, P., X. Le Pichon, and C. Rangin (1994), Indochina block and the collision of India and Eurasia, Geology, 22, 27-30.

Iwakuni, M., T. Kato, H. Takiguchi, T. Nakaegawa, and M. Satomura (2004), Crustal deformation in Thailand and tectonics of Indochina peninsula as seen from GPS observations, Geophys. Res. Lett., 31, L11612, doi:10.1029/2004GL020347.

Kennett, B. L. N., and E. R. Engdahl (1991), Travel times for global earthquake location and phase identification, Geophys J. Int., 105, 429-465.

Langston, C. A. (1979), Structure under Mount Rainier, Washington, inferred from teleseismic body waves, J. Geophys. Res., 84, 4749-4762.

Lebedev, S., and G. Nolet (2003), Upper mantle beneath Southeast Asia from S velocity tomography, J. Geophys. Res., 108(B1), 2048, doi:10.1029/2000JB000073.

Li, Y., Q. Wu, X. Tian, R. Zhang, J. Pan, and R. Zeng (2009), Crustal strucure in the Yunnan region determined by modeling receiver functions (in Chinese), Chin. J. Geophys., 52, 68-80.

Ozacar, A. A., and G. Zandt (2004), Crustal seismic anisotropy in central Tibet: implications for deformational style and flow in the crust, Geophys. Res. Lett., 31, L23601, doi:10.1029/2004GL021096. 
Savage, M. K. (1998), Lower crustal anisotropy or dipping layers? Effects on receiver functions and a case study in New Zealand, J. Geophys. Res., 103, 15,069-15,087.

Tapponnier, P., G. Peltzer, A. Y. Le Dain, R. Armijo, and P. Cobbold (1982), Propagating extrusion tectonics in Asia: New insights from simple experiments with plasticine, Geology, 10, 611-616.

Teng, J., R. Zeng, Y. Yan, and H. Zhang (2003), Depth distribution of Moho and tectonic framework in eastern Asia continent and its ajacent ocean areas, Sci. China D, 46, 428-446.

$\mathrm{Xu}, \mathrm{L} ., \mathrm{S}$. Rondenay, and R. D. Van der Hilst (2007), Structure of the crust beneath the southeastern Tibetan Plateau from teleseismic receiver functions, Phys. Earth Planet. Inter., 165, 176-193.
Zandt, G., and C. J. Ammon (1995), Continental crust composition constrained by measurements of crustal Poisson's ratio, Nature, 374, $152-154$.

Zhu, L., and H. Kanamori (2000), Moho depth variation in southern California from teleseismic receiver functions, J. Geophys. Res., 105, 2969-2980.

L. Bai and J. Ritsema, Department of Geological Sciences, University of Michigan, Ann Arbor, MI 48109, USA.

X. Tian, Institute of Geology and Geophysics, Chinese Academy of Sciences, Beijing 100864, China. 